\title{
Proliferating cell nuclear antigen (PCNA): a new marker to study human colonic cell proliferation
}

\author{
F J G M Kubben, A Peeters-Haesevoets, L G J B Engels, C G M I Baeten, B Schutte, \\ J W Arends, R W Stockbrügger, G H Blijham
}

\begin{abstract}
Immunohistochemistry of the $S$ phase related proliferating cell nuclear antigen (PCNA) was studied as an alternative to ex-vivo bromodeoxyuridine (BrdU) immunohistochemistry for assessment of human colonic cell proliferation. From 16 subjects without colonic disease biopsy specimens were collected from five different sites along the colorectum and processed for BrdU and PCNA immunohistochemistry. The mean proliferation index of PCNA was significantly higher at $133 \%$ of the value obtained with BrdU. There was, however, a good correlation between the results from both techniques $(r=0.6275 ; p<0.05)$. Decrease in proliferation index along the colorectum was seen with both staining methods but was clearer with PCNA immunohistochemistry (caecum/ascending colon $v$ rectum: $12.0 v 7.2 ; p<0.004)$. The total number of crypt cells also decreased from proximal to distal $(134$ to $128 ; p<0.06)$ but at no site correlated significantly with the proliferation index. It is concluded that in clinical cell kinetic studies staining for PCNA may serve as an attractive alternative to the BrdU incorporation assay.

(Gut 1994; 35: 530-535)
\end{abstract}

In experimental carcinogenesis, changes in the proliferative characteristics of the colonic mucosa have been found to come before the development of frank neoplasia. ${ }^{1-3}$ In subjects at risk for the development of colorectal carcinoma similar changes have been found including increased proliferation and an abnormal distribution of proliferating cells along the colonic crypts. Therefore, study of the proliferative phenotype may become an important clinical marker to identify subjects at risk to develop neoplasia and to determine early effects of treatment aimed at reducing this risk. ${ }^{46}$

For many years ex vivo labelling with tritiated thymidine followed by autoradiography has been used to determine the percentage of $S$ phase cells or labelling index. This technique, however, is labour intensive and requires facilities to handle radioactivity. An improvement was achieved by ex vivo labelling with bromodeoxyuridine (BrdU), a thymidine analogue and its visualisation with a monoclonal antibody using routine immunohistochemical methods. ${ }^{7-9}$ Together with the difficulties in fixation and processing, partly adjustable by enzymatic pretreatment, the ex vivo labelling step remains a potential source for differences in labelling efficacy.

Proliferating cell nuclear antigen (PCNA) is an intranuclear $36 \mathrm{kD}$ polypeptide $\mathrm{e}^{10}$ whose expression $^{12}$ and synthesis ${ }^{13}$ is linked with cell proliferation. Flow cytometry on the human lymphoblastoid cell line Molt 4 using anti-PCNA monoclonal antibody and propidiumiodide showed predominant expression of PCNA during the $S$ phase of the cell cycle but also during the late G1 and early G2 phase. ${ }^{14}$

In this study human colorectal mucosa was ex vivo labelled with BrdU to investigate the correlation between BrdU and PCNA immunoreactivity and the relation between these parameters and crypt height. Biopsy specimens were obtained in a programmed way from various sites over the entire colorectum to establish proliferative parameters in relation to site.

\section{Materials and methods}

\section{BIOPSY SPECIMENS}

Biopsy specimens of endoscopically normal colonic mucosa were taken at five different sites from proximal to distal in the colorectum (ascending, transverse, and descending colon, sigmoid, and rectum) of 16 subjects who had had diagnostic colonoscopy because of abdominal complaints and who were found not to have any organic colonic disorders (seven men, nine women, mean age 49 years, range 17 to 76 ). All specimens were taken by one endoscopist (LGJBE) and completely processed by the same technician (AP-H). Specimens were immediately placed in RPMI 1640 tissue culture medium containing $10 \%$ fetal calf serum, $20 \mu \mathrm{M}$ 5-fluoro-uracil, $20 \mu \mathrm{M}$ bromodeoxyuridine (Serva, Heidelberg, Germany), and $0.9 \%$ hydrogenperoxide during one hour at $37^{\circ} \mathrm{C}$.

The composition of the tissue culture medium was based on a $3 \times 3$ experiment in which optimal conditions for ex vivo labelling of mouse and human tissue with BrdU were determined. Intestinal specimens were incubated in RPMI 1640 medium containing $10 \%$ fetal calf serum and concentrations of 1,2 or $\left.3 \times 10^{-5}\right) \mathrm{M} \mathrm{BrdU}$ and $0.5,1$ or $210^{-5}$ ) $M$-fluorouracil. We found that the addition of hydrogen peroxide seemed to improve the label uptake, therefore in this experiment hydrogen peroxide $30 \%$ was added to final concentrations of $0 \cdot 3,0.9$, and $1.8 \%$ respectively. Specimens were immersion fixed in $70 \%$ ethanol for at least 24 hours. Best results with regard to immunoreactivity and morphology, were obtained by incubation with RPMI 1640 medium containing $10 \%$ fetal calf serum, $\left.2 \times 10^{-5}\right) M$ 5-fluoro-uracil, and $0.9 \%$ hydrogen peroxide.

As maximum incorporation of $\mathrm{BrdU}$ can be expected after depletion of the endogenous pool 
of thymidine monophosphate by inhibition of its de novo synthesis with 5-fluorodeoxyuridine, ${ }^{15} 16$ addition of 5-fluorouracil, which is intracellularily converted to 5-fluorodeoxyuridine, resulted in slightly better immunostaining without differences in proliferation index.

Comparison of in vivo labelling with tritiated

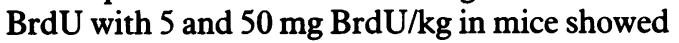
a sensitivity of 94.8 and $98.4 \%$ and a specificity of 99.6 and $99.4 \%$ respectively. ${ }^{9}$ Comparison of ex and in vivo labelling with BrdU in mice showed a very good correlation between both techniques. From five hours of ex vivo labelling onwards, the proliferation index decreased in comparison with the proliferation index obtained by in vivo labelling.

Thereafter the specimens were immersion fixed in ethanol $70 \%$ at $4^{\circ} \mathrm{C}$, and stored at the same temperature. Fixation and processing for anti-BrdU immunohistochemistry are potential sources of variability in proliferation index. It was previously shown that tissues fixed in denaturing fixatives such as ethanol or Carnoy's fluid invariably showed immunoreactivity, while cross linking agents, for example, formalin and glutaraldehyde showed weak or no reaction at all. By pretreatment of tissue sections with pepsin, the staining intensity of crypt cells was increased after formalin fixation. The effect of pepsin digestion can be explained by a facilitation of DNA denaturation as a result of digestion of chromatin associated proteins. ${ }^{17}$ Finally, specimens were embedded in paraplast and cut at $2 \mu \mathrm{M}$ on a Reichert-Jung microtome (type 2540 , variation according to manufacturer's specifications $10 \%$ ).

\section{IMMUNOHISTOCHEMISTRY}

After removal of paraffin and rehydration, endogenous peroxidase was blocked in $0.3 \%$ hydrogenperoxide in methanol for 20 minutes. In the slides to be processed for anti-BrdU immunohistochemistry, DNA was hydrolysed in $2 \mathrm{~N}$

Figure 1: The running average of proliferation index in normal looking colonic mucosa of one subject.

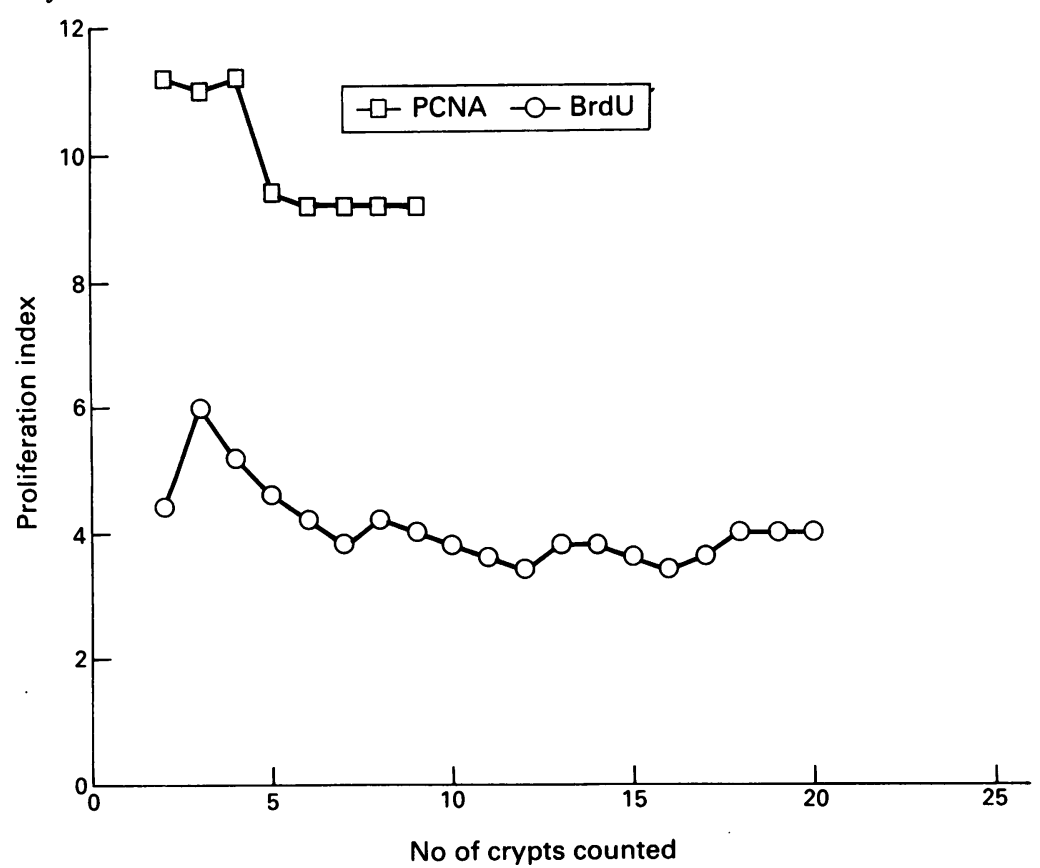

$\mathrm{HCl}$ for 30 minutes at $37^{\circ} \mathrm{C}$ and sections were subsequently rinsed in $0.1 \mathrm{M}$ sodium tetraborate (pH 8.5). After incubation with a monoclonal anti-BrdU antibody ${ }^{9}$ or an IgM anti-PCNA antibody (clone 19A2, Coulter Electronics, Mijdrecht, The Netherlands ${ }^{11}$ ) for one hour at $37^{\circ} \mathrm{C}$, sections were incubated with rabbit antimouse IgG-HRP (one hour, room temperature). As peroxidase substrate $3,3^{\prime}$ diaminobenzidinetetrahydrochloride (Sigma, St Louis, USA) was used according to Graham and Karnovsky. ${ }^{18}$ Nuclei were counterstained with haematoxylin.

Positive controls included in vivo labelled specimen of mice or rat and ex vivo labelled human biopsy specimens known to be positive. Negative controls included human and rat specimen with and without incorporated BrdU, leaving out the anti-BrdU or anti-PCNA antibody or the conjugated rabbit anti-mouse polyclonal antibody. Only slides of batches with correct controls were evaluated.

SCORING AND METHOD OF COUNTING OF STAINED SECTIONS

Only U shaped longitudinally cut crypts with open lumina along the crypt axis, with the base of the crypt touching the muscularis mucosae, were evaluated. The total number of immunoreactive nuclei/crypt was counted as well as the total number of crypt nuclei. To avoid selection bias, all crypts showing at least one BrdU immunoreactive nucleus were included and compared with the appropriate PCNA immunoreactive nuclei. The proliferation index of that crypt was defined as the percentage immunoreactive crypt cells of the total number of crypt cells. In addition, the distribution of immunoreactive cells along the crypt lining was studied by dividing the crypt into three parts (lower, middle, and upper) and by determining in what part the labelled cells were localised predominantly. Slides were analysed by one investigator (FJGMK) with a blinded method. The repeatability coefficient ${ }^{19}$ was calculated at $1.08 \%$ $(n=10)$, which means that $95 \%$ of differences in repeated measurements (intraobserver variability) are expected to be less than $1.08 \% .{ }^{20}$ Data were analysed as immunoreactive nuclei/crypt, not per number of crypt cells. Based on the 'running average'21 data in three patients, we could show that six well oriented and well stained crypts were sufficient to obtain a reliable proliferation index (Fig 1). Therefore the analysis was restricted to biopsy specimens that fulfilled this criterium. Paired and unpaired $t$ tests were used to compare BrdU/PCNA staining and staining at different colonic sites respectively.

\section{Results}

BrdU staining was successful in only $44 \%$ of well oriented crypts compared with $86 \%$ with PCNA (Table I). In some mucosal sections good BrdU staining was seen in some parts whereas in other parts crypts were clearly negative. This shows that labelling inefficiency rather than immunohistochemistry problems contributed to the comparatively low success rate. This is substantiated by the high success rate of PCNA staining, 
TABLE I Success rate of BrdU and PCNA immunohistochemistry

\begin{tabular}{|c|c|c|}
\hline & \multicolumn{2}{|l|}{ Staining } \\
\hline & $B r d U$ & PCNA \\
\hline $\begin{array}{l}\text { No of crypts examined } \\
\text { No of positive crypts }\end{array}$ & $\begin{array}{l}2035 \\
901(44 \%)\end{array}$ & $\begin{array}{l}761 \\
651(86 \%)\end{array}$ \\
\hline
\end{tabular}

BrdU = bromodeoxyuridine.

PCNA = proliferating cell nuclear antigen.

TABLE II Comparison of BrdU and PCNA immunohistochemistry of the human colorectal mucosa

\begin{tabular}{llll}
\hline Staining & $\begin{array}{l}\text { Mean profliferation } \\
\text { index }\end{array}$ & SD & Range \\
\hline BrdU & $6 \cdot 9$ & $2 \cdot 4$ & $2 \cdot 1-12 \cdot 6$ \\
PCNA & $9 \cdot 2^{\star}$ & $3 \cdot 6$ & $4 \cdot 0-16 \cdot 1$ \\
\hline
\end{tabular}

Sixteen specimens with at least six evaluable crypts for each staining. ${ }^{\star} \mathrm{p}=0.0004$ (paired $t$ test); abbreviations as in Table I.

which is not dependent on a previous ex vivo labelling step.

BrdU and PCNA staining were then compared on the single crypt level. For this we selected 16 specimens for which at least six crypts with BrdU were available, thereby making a direct comparison with PCNA possible (Table II). The mean

Figure 2: Correlation BrdU/PCNA

immunohistochemistry.
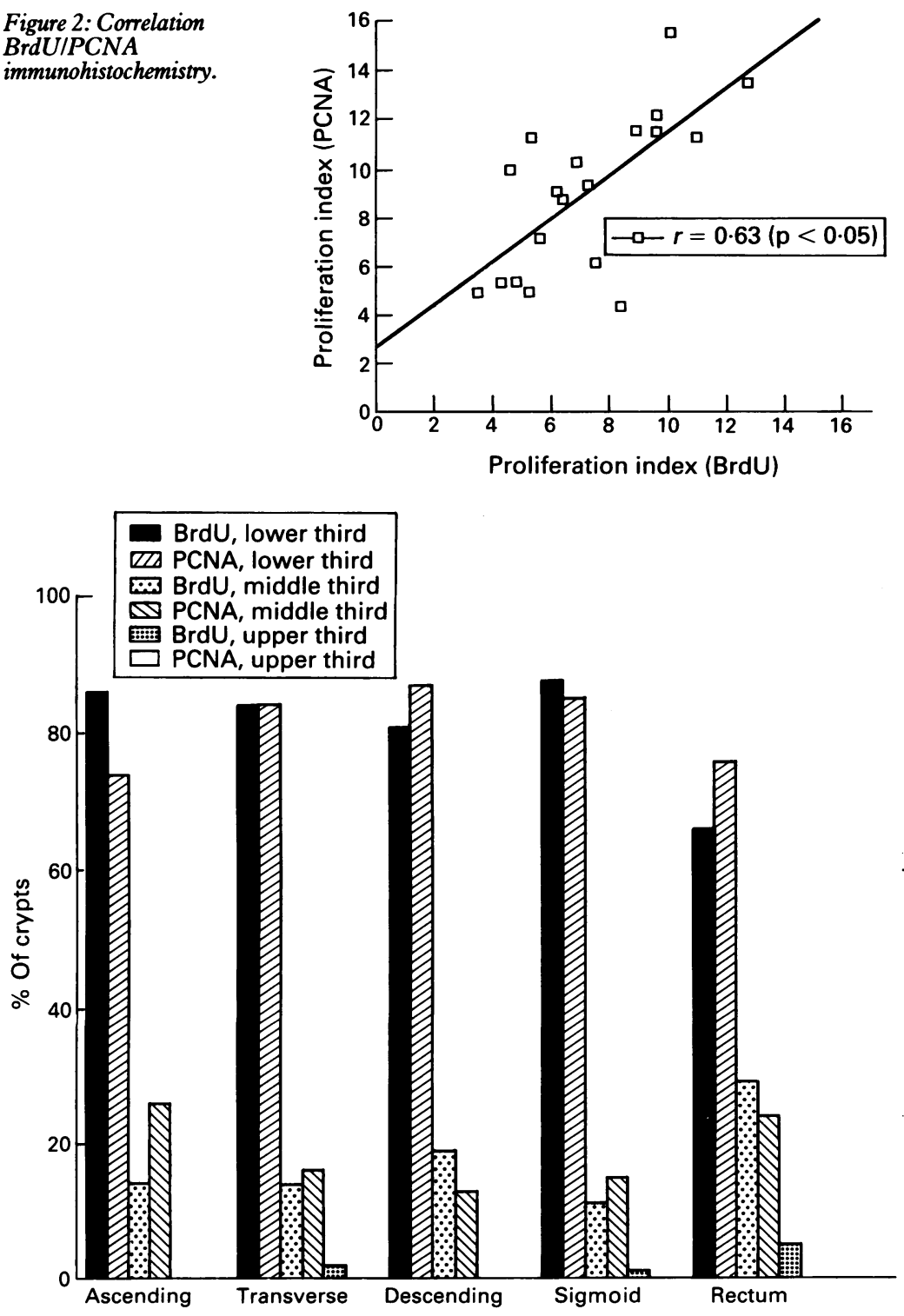

Figure 3: Predominant site of BrdU or PCNA staining along colorectal crypts.
PCNA proliferation index was significantly higher at $133 \%$ of the BrdU proliferation index. This difference seems to be systematic as the correlation matrix is showing significant correlation $(r=0.63 ; p<0.05)$ (Fig 2). Furthermore, the distribution of BrdU and PCNA immunoreactive cells along the colonic crypt was similar. In Figure 3, this distribution over the lower, middle, and upper compartments of the colonic crypt is depicted, showing in both cases that $80 \%$ of these cells are located on the lower third and virtually none in the upper third. This is illustrated (Fig 4) in two serial sections of the same colonic crypt.

BrdU and PCNA immunoreactivity were determined in relation to the site along the human colorectum (Fig 5). Both proliferation indices decreased from proximal to distal; this was most pronounced for the PCNA staining index with a decrease of $40 \%$ between the right sided colon and the rectum. For the PCNA staining index, the differences between rectum and sigmoid were not significant; differences with and between the descending, transverse, and ascending colon were, however, statistically significant ( $p=0.0004$ and $p=0.02$ respectively).

Crypt height defined as the number of mucosal cells present in one column of a longitudinally cut crypt, was also determined along the entire colorectum (see Fig 5). Crypt height was the lowest in the rectum, but the differences were not statistically significant compared with descending, transverse, and ascending colon $(p=0.06)$. BrdU immunoreactivity (correlation coefficient $0.0008, p$ value not significant) and PCNA immunoreactivity (correlation coefficient $0 \cdot 1616$, $p$ value not significant) were not significantly correlated with the crypt height.

\section{Discussion}

Changes in proliferative characteristics of colorectal mucosa are important markers for an increased risk of developing neoplasia. In addition to the problems in fixation, the ex vivo labelling step with BrdU is an important source of problems in the implementation of anti-BrdU immunohistochemistry for assessment of proliferation characteristics in routine endoscopy laboratories. More importantly, poor penetration of the DNA precursors or the finish of DNA synthesis in the ex vivo situation may cause the labelling to be heterogenous and of low efficacy. For instance in this study less than $50 \%$ of evaluable crypts was adequately labelled with BrdU despite measures to facilitate labelling by performing incubation next to the endoscopy room, by using a rich incubation medium, and by adding hydrogen peroxide to improve oxygen tension. This clearly illustrates the need for the development of logistically more easy and technically more reliable ways to determine proliferative characteristics. Our experiments were carried out to validate the use of PCNA immunohistochemistry as an alternative proliferative assay for human colorectal mucosa.

In Table III, some ex vivo cell kinetic studies on endoscopically and histologically normal human colonic tissue in normal subjects are summarised, showing a proliferation index 

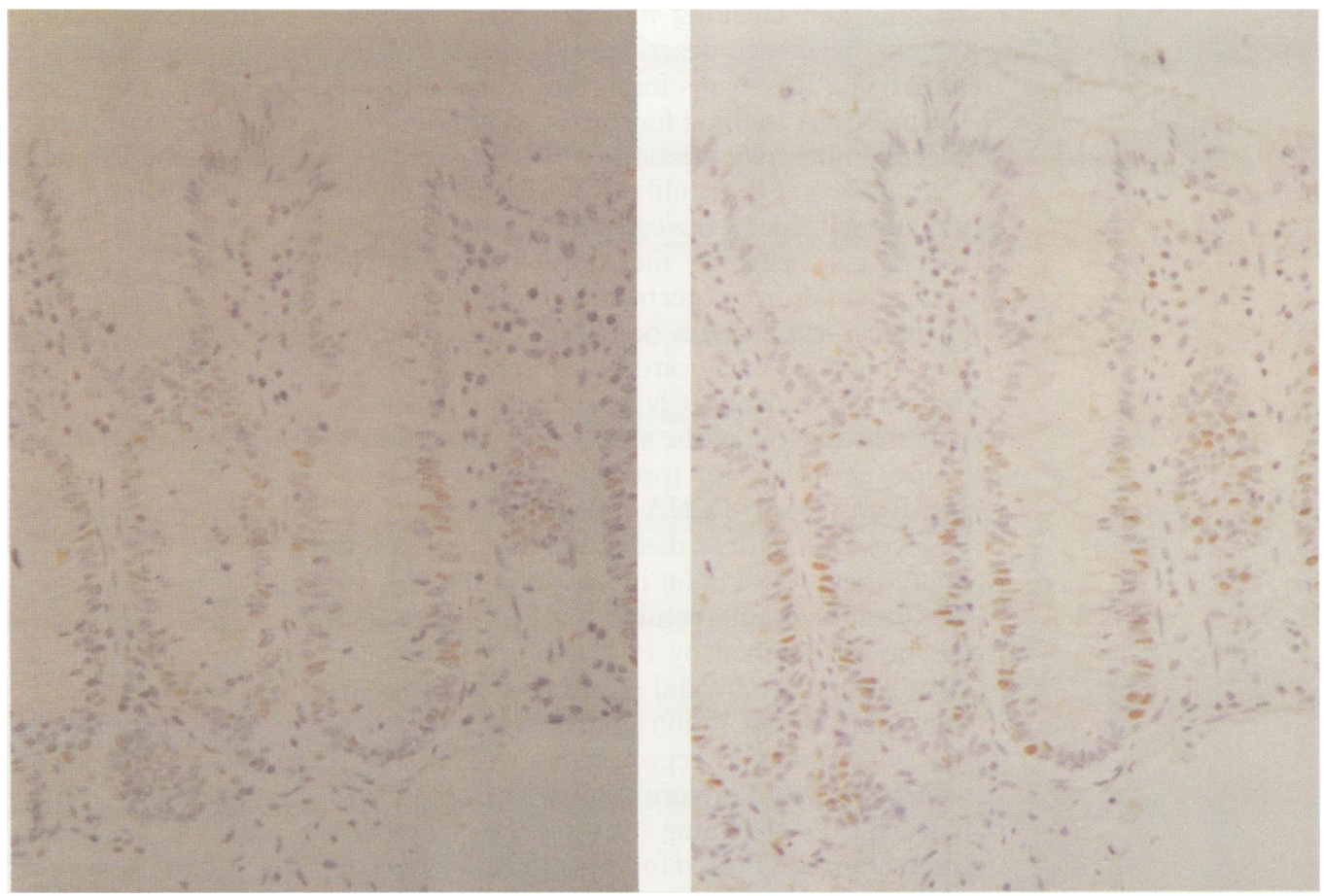

Figure 4: BrdU (left) and PCNA (right) immunoreactivity in two serial sections of the same colonic crypt.

ranging from $4 \cdot 9-11 \cdot 3 \%$ for tritiated thymidine labelling and from 5.9-6.9 for BrdU. The proliferation index with BrdU was slightly higher than reported in published works (showing that the simple ex vivo labelling procedure used is at least as efficient as more sophisticated alternatives commonly used ${ }^{21}{ }^{27}$ but still in the range of values obtained using tritiated thymidine).

By comparing PCNA and BrdU immunoreactivity in a systematic way differences as well as similarities were found. The main difference is the frequency of immunoreactive cells that was almost always higher in PCNA compared with BrdU stained crypts. The two proliferation indices significantly correlated, however, showing that the enhanced detection of PCNA immunoreactivity is a systematic rather than a random phenomenon. Immunohistochemical studies using IgG type anti-PCNA antibodies and BrdU incorporation showed a good correlation in stimulated peripheral blood mononuclear cells. ${ }^{28}$ In tissues fixed in methanol the PCNA proliferation index did not differ by more than 6\% from the tritiated thymidine labelling index and crypt height along index. ${ }^{29}$ In an animal study, using normal rat the normal human colon.

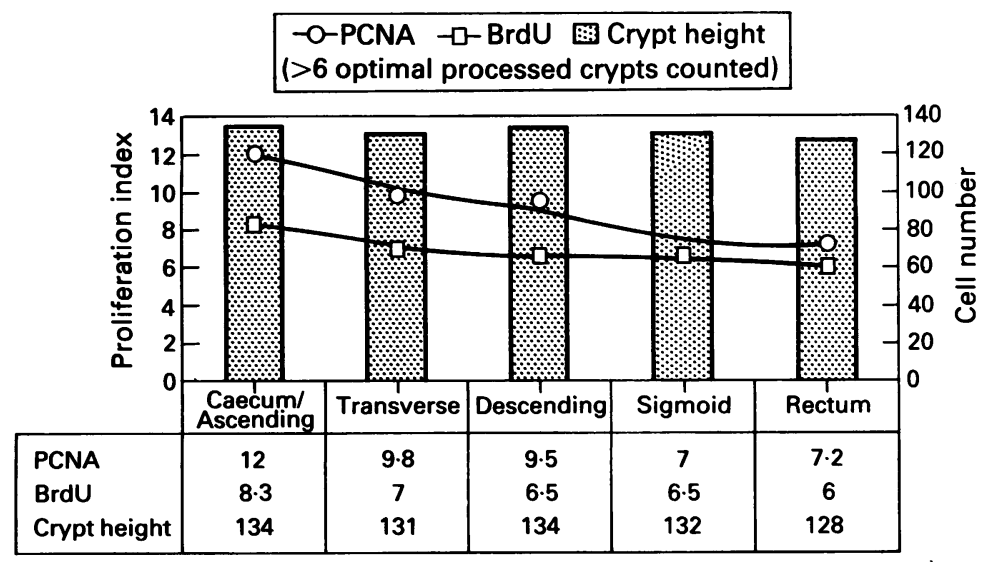

colon after in vivo labelling with $\mathrm{BrdU}$ and tritiated thymidine no significant differences between the labelling indices with these two DNA precursors and PCNA immunoreactivity was found. ${ }^{30}$ Another animal study showed a strong correlation between in vivo labelling with tritiated thymidine and PCNA $(r=0.982 ; \mathrm{p}=$ 0.018 ) and between location of maximal staining for PCNA and tritiated thymidine $(r=0.997$; $\mathrm{p}<0.05){ }^{31}$ The conclusion from these studies, that PCNA immunostaining may be a good alternative for BrdU or tritiated thymidine labelling is supported by our findings, showing a good correlation between BrdU and PCNA proliferation index along the entire colorectum. The systematic difference of around $2 \%$ may be the consequence of poor penetration of the label, early cessation of DNA synthesis or the immunoreactive PCNA present in late G1 or G2 cells. The fact that with in vivo labelling the $\mathrm{BrdU}$ and PCNA proliferation index are equal, at least in rats, suggests that the first explanation is more probable. It has to be emphasised, however, that with different fixatives, for example, formalin, with differences in immunocytochemical procedures, and with different cell sources, for example, cell lines, discordances between PCNA

TABLE III Proliferation index of endoscopically and histologically normal human colonic mucosa in normal subjects

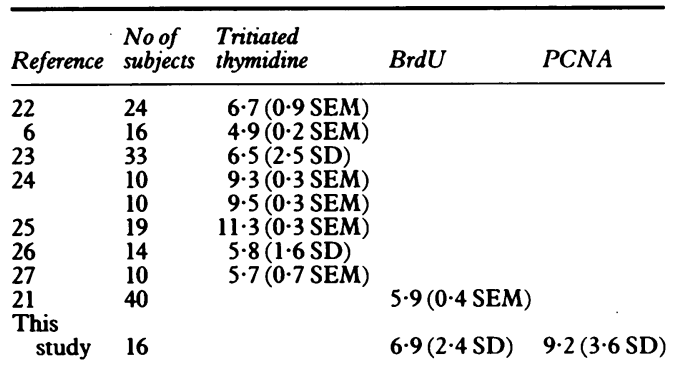

Abbreviations as in Table I. 
staining and labelling indices with DNA precursors have been described by others. For the time being it remains important to validate the use of PCNA staining for the tissue type and the species under investigation.

Extension of the proliferative compartment to the luminal side of the crypt has been described as being a sensitive measure of proliferative abnormalities in colorectal mucosa. It is also one of the earliest changes occurring during induction of colonic adenocardinoma in mice by $1,2-$ dimethylhydrazine. It is therefore important to note that staining of the middle and upper thirds of the crypt was not appreciably different with anti-BrdU or anti-PCNA antibodies.

Terpstra et al described a decrease in tritiated thymidine proliferation index along the normal looking human colorectum. ${ }^{6}$ For $\mathrm{BrdU}$, the same has been described by Potten et al..$^{32}$ If PCNA staining is to be a valid alternative to BrdU or thymidine incorporation studies, it is mandatory that this finding is reproducible with the new technique. We therefore compared BrdU labelling and PCNA staining at various sites along the colorectum and indeed found both parameters of proliferation to decrease from the ascending colon to the rectum. This decrease was more prominent with PCNA staining, which underscores the validity of this technique to measure differences in proliferation.

As Figure 2 shows, small percentages of crypts with BrdU but without PCNA in the upper third of the crypts were seen, but only in the rectosigmoid region. As the PCNA proliferation index is generally higher then that with BrdU, this seems surprising. Figure 5 shows, however, a more prominent decrease in PCNA proliferation index compared with $\mathrm{BrdU}$, suggesting that the number of cells in G1 or G2M phase of the cell cyclus decreases from proximal to distal in the human colon. This would explain why, in the distal colon, BrdU immunoreactive nuclei are seen without simultaneous PCNA immunoreactive nuclei.

The crypts of mice with a genetic susceptibility to develop colorectal cancer are not only characterised by an increased proliferation but also by increased crypt size. ${ }^{33}$ This suggests that in these animals the increased proliferation is not the result of an increased cell loss, but rather a reflection of an inherently increased proliferative activity. We examined whether the crypt height in the human colorectal mucosa is related to proliferative activity as reflected in the BrdU labelling index or PCNA staining index. It was found that the crypt height, expressed as the number of cells/colonic crypt was constant over the colorectum and in individual cases did not correlate with the markers of proliferation. It remains to be investigated if the crypt height is an alternative or additional biomarker for the risk of developing colorectal adenoma or carcinoma.

In summary, in the human colorectum the rate and site of cell proliferation determined by immunostaining for PCNA reflects the proliferative activity determined by labelling with the DNA precursor BrdU. The technique avoids the use of an ex vivo labelling step and is therefore technically more easy and less amenable to disturbances because of inadequate penetration of the label or early cessation of DNA synthesis. It remains to be seen if PCNA immunostaining may indeed substitute for DNA precursor labelling in studies aimed at identifying patients at risk of develping colorectal neoplasia.

We are indebted to Ms J Buset (Department of Internal Medicine) for technical assistance and to $\mathrm{H}$ Schouten, $\mathrm{PhD}$ (Department of Medical Information and Statistics, University of Limburg, Medical Information and Staticht) for statistical advice.

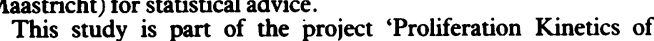

This study is part of the project 'Proliferation Kinetics of
Preneoplastic and Neoplastic Conditions of the Colon with or Preneoplastic and Neoplastic Conditions of the Colon with or
without Oral Calcium Suppletion (IKL 88/05)' of the Dutch without Oral Calcium Suppletion (IKL $88 / 05$ ) of the Dutch The Netherlands.

This study was partly presented at the European Digestive Disease Week, Amsterdam, 23 October 1991 (European fournal of Gastroenterology and Hepatology 1991; 3 suppl 1: S59).

1 Deschner EE, Moshen AP. Significance of labelling index and labelling distribution on kinetic parameters in colorecta mucosa of cancer patients and DMH-treated animals. Cancer 1982; 50: 1136-41.

2 McGarrity TJ, Peiffer LP, Colony PC. Cellular proliferation in proximal and distal rat colon during 1,2-dimethylhydrazineinduced carcinogenesis. Gastroenterology 1988; 95; 343-8.

3 Richards TC. Early changes in the dynamics of crypt cell populations in mouse colon following administration of 1,2 populations in mouse colon following administra

4 Lipkin M, Blattner WA, Gardner EJ, Bert RW, Lynch H, Deschner $\mathrm{E}$, et al. Classification and risk assessment of individuals with familial polyposis, Gardner syndrome, and individuals with familial polyposis, Gardner syndrome, and
familial non-polyposis colon cancer from [ $3 \mathrm{H}]-\mathrm{dThd}-$ familial non-polyposis colon cancer from [3H]-dThdlabelling pat

5 Maskens AP, Deschner EE. Tritiated thymidine incorporation into epithelial cells of normal appearing colorecta mucosa of cancer patients. $\mathcal{F}$ Natl Cancer Inst 1977; 58 $1221-4$.

6 Terpstra OT, van Blankenstein M, Dees J, Eilers GAM Abnormal patterns of cell proliferation in the entire colonic mucosa of patients with colon adenoma or cancer. Gastroenterology 1987; 92: 704-8.

7 Gratzner $H$. Monoclonal antibody against 5-bromo- and 5-iododeoxyuridine: a new reagent for detection of DNA 5-iododeoxyuridine: a new reagent
replication. Science 1982; 218: 474-5.

8 Schutte B, Reynders MMJ, van Assche CLMVJ, Hupperets PSGJ, Bosman FT, Blijham GH. Studies with antibromodeoxyuridine antibodies. I. An improved method for the immunochemical detection of BrdU labelled nuclei using low cytometry. Cytometry 1987; 8: 372-6.

9 Schutte B, Reynders MMJ, Bosman FT, Blijham GH. Studies with anti-bromodeoxuridine antibodies. II. Simultaneous immunocytochemical detection of antigen expression and DNA synthesis by in vivo labelling of mouse intestina mucosa. F Histochem Cytochem 1987; 35: 371-4.

10 Takasaki Y, Fishwild D, Tan EM. Characterization of proliferating cell nuclear antigen recognized by auto-antibodies in lupus sera. $₹$ Exp Med 1984; 159: 981-92.

11 Ogata K, Ogata Y, Nakamura RN, Tan EM. Purification and N-terminal amino acid sequence of proliferating cell nuclear N-terminal amino acid sequence of proliferating cell nuclear antigen (PCNA/cyclin) and development of ELISA

12 Miyachi K, Fritzler MJ, Tan EM. Antibody to a nuclear antigen in proliferating cells. F Immunol 1978; 121: 2228 .

13 Celis J, Bravo R. Synthesis of the nuclear protein cyclin in growing, sensecent and morphologically transformed human skin fibroblasts. FEBS Lett 1984; 165: 21-5.

14 Kurki P, Ogata K, Tan EM. Monoclonal antibodies to proliferating cell nuclear antigen (PCNA/cyclin) as probes for proliferating cells by immunofluorescence microscopy and flow cytometry. F Immunol Methods 1988; 109: 49-59.

15 van Dierendock J-H, Keyzer R, van de Velde CJH, Cornelisse CJ. Subdivision of S-phase by analysis of nuclear 5bromodeoxyuridine staining patterns. Cytometry 1989; 10: 143-50.

16 Doermer $P$, Ellwart J. Effect of 5-fluoro-2'-deoxyuridine (FdUrd) on 5-bromo-2'-deoxyuridine (BrdUrd) incorporaFdUrd) on S-bromo-2 -deoxyuridine (BrdUrd) incorporation into DNA measured with a monoclonal BrdUrd antibody and by the Bd

17 Schutte B, Reijnders MMJ, Bosman FT, Blijham GH. The effect of tissue fixation on anti-bromodeoxyuridine immunohistochemistry. F Histochem Cytochem 1987; 35: 1343-5.

18 Graham RC, Karnovsky MC. The early steps of absorption of injected horseradish peroxidase in the proximal tubules of the mouse kidney: ultrastructural cytochemistry by a new technique. F Histochem Cytochem 1966; 14: 291-8.

19 British Standards Institution. Precision of test methods 1: Guide for the determination and reproducibility for a standard test method (BS 5497, part 1). London: BSI, 1979.

20 Bland JM, Altman DG. Statistical methods for assessing agreement between two methods of clinical measurement. Lancet 1986; i: 307-10.

21 Welberg JWM, de Vries EGE, Hardonk MJ, Mulder NH, Grond $\mathrm{J}$, Zwart N, et al. Proliferation rate of colonic mucosa in normal subjects and patients with colonic neoplasms: a in normal subjects and patients with colonic neoplasms: a
refined immunohistochemical method. $\mathcal{F}$ Clin Pathol 1990; 43: $453-6$. 
22 Lipkin M, Enker WE, Winawer SJ. Tritiated-thymidine labelling of rectal epithelial cells in 'non-prep' biopsies of individuals at increased risk for colonic neoplasia. Cancer Lett 1987; 37: 153-61.

23 Deschner EE, Godbold J, Lynch H. Rectal epithelial cell proliferation in a group of young adults. Influence of age and genetic risk for colon cancer. Cancer 1988; 61: age and

24 Roncucci L, Ponz de Leon M, Scalmati A, Malagoli G, Pratissoli S, Perini M, et al. The influence of age on colonic epithelial cell proliferation. Cancer 1988; 62: 2373-7.

25 Ponz de Leon M, Roncucci L, Di Donato P, Tassi L, Smerieri $\mathrm{O}$, Amorico MG, et al. Pattern of epithelial cell proliferation in colorectal mucosa of normal subjecrs and of patients with adenomatous polyps or cancer of the large bowel. Cancer Res $1988 ; 48: 4121-6$.

26 Stadler J, Sing Yeung K, Furrer R, Marcon N, Himal HS, Bruce WR. Proliferative activity of rectal mucosa and soluble fecal bile acids in patients with normal colons and in patients with colonic polyps or cancer. Cancer Lett 1988; 38: patients

27 Risio M, Coverlizza S, Ferrari A, Candelaresi GL, Rossini FP. Immunohistochemical study of epithelial cell proliferation in hyperplastic polyps, adenomas, and adenocarcinomas of the large bowel. Gastroenterology 1988; 94: 899-906.
28 Hall PA, Levison DA, Woods AL, Yu CC, Kellock DB, Watkins JA, et al. Proliferating cell nuclear antigen (PCNA) immunolocalization in paraffin sections: an index of cell proliferation with evidence of deregulated expression in proliferation with evidence of deregulated
some neoplasms. F Pathol 1990; 162: 285-94.

29 Galand P, Degraef C. Cyclin/PCNA immunostaining as an alternative to tritiated thymidine pulse labelling for marking alternative to tritiated thymidine pulse labelling for marking
$\mathrm{S}$-phase cells in paraffin sections from animal and human S-phase cells in paraffin sections from
tissues. Cell Tiss Kinet 1989; 22: 383-92.

30 Richter F, Richter A, Yang K, Lipkin M. Colonic epithelial cell proliferation measured with BrdU, PCNA and [3HY]dThD. Eur f Gastroenterol Hepatol 1991; 3 (suppl 1): S67.

31 Yamada K, Yoshitake K, Sato M, Ahnen DJ. Proliferating cell nuclear angiten expression in normal, preneoplastic, and neoplastic colonic epithelium of the rat. Gastroenterology 1992; 103: 160-7.

32 Potten CS, Kellett M, Rew DA, Roberts SA. Proliferation in human gastrointestinal epithelium using bromodeoxyuridine in vivo: dat for different sites, proximity to a deoxyuridine in vivo: data for different sites, proximity to a

33 Glickman LT, Senterman MK, Fleiszer DM. 1,2Dimethylhrazine-induced nuclear aberrations in $A / J$ and C57BL/6J mouse colonic crypts. $\mathcal{F}$ Natl Cancer Inst 1987; 79: 499-507. 